\title{
Sliding Mode Control for Therapeutic Pool Model Control System
}

\author{
Munadi $^{1}$, Henry Kristianto ${ }^{1}$, Mochammad Ariyanto ${ }^{1}$ \\ ${ }^{1}$ Department of Mechanical Engineering, \\ Diponegoro University \\ Tembalang, Semarang, 50275, Indonesia \\ munadi@undip.ac.id, henrykristianto1994@gmail.com
}

\author{
Ismoyo Haryanto ${ }^{1}$, Hari Peni Julianti ${ }^{2}$ \\ ${ }^{2}$ Departement of Public Health and Preventive Medicine, \\ Diponegoro University \\ Semarang, Indonesia
}

\begin{abstract}
In this study we consider the robust control of a therapeutic pool model using Sliding Mode Control (SMC). Therapeutic pool is a warm water pool used for stroke therapy. It makes exercises for stroke patients easier than done outside water because of the water buoyant force which reduces human weight. The therapeutic pool which is designed in this study has two inlets and an outlet for drainage. The first inlet is for the hot water flow and the second is for the cold water flow. The two water flows are mixed in the therapeutic pool. The controlled variable is the mixed water temperature in therapeutic pool. Unsteady thermodynamics and mass balance are used to mathematically model the therapeutic pool. The SMC controller is designed to reject disturbances due to heat transfer from the mixed water to surrounding through the contacting surface between water and the free air stream. The usefulness of this technique is illustrated with a simulation. Desired temperature of therapeutic pool is successfully reached and maintained steady. The performance of SMC controller is compared to conventional PID (Proportional Integral Derivative) controller and the neural model of the conventional one.
\end{abstract}

Keywords-component; robust; SMC; therapeutic pool.

\section{INTRODUCTION}

The therapeutic pool is not rare to find in many health facilities all over the world. Therapeutic pool is used by stroke patients to do rehabilitation exercises in warm water. The type of exercise is formulated according to [1]. As it can be summarized, the main parameters are exercise types, the sequences, intensities, break time, warming up and cooling down. The mixed water temperature is also important, which is noted in [2], the convenient temperature range is from 31-34 ${ }^{0} \mathrm{C}$. The problem of controlling amount of hot and cold water to produce a mixture having a desired temperature is familiar to everyone. In example, the problem appears as in $[3,4]$ which multivariable SMC controller is used [5]. In this paper we analyze the problem of obtaining mixed water temperature by modelling the therapeutic pool with differential equations. The differential equations are derived from the thermodynamics principle and mass balance equation.

Schematic diagram of therapeutic pool can be described by using the pool with two input of hot water valve and cold water input, and one outlet water valve. The controlled input is valve position of the hot water flow, meanwhile valve position of the cold water flow is kept constant. We use two DC motors for controlling two valves of hot water and cold water. We have also applied the DC motor because it is the most widely applied actuator in automation systems such as in the control position of an arm robot manipulator [6, 7].

In this therapeutic pool model, the flow rate and temperature of the hot water and cold water are kept constant. The variation of water temperature is used for testing the controller. The other disturbance to be assumed is due to heat transfer from the mixed water to surrounding through the contacting surface between water and free stream of air. The empirical equation of convective heat transfer coefficient can be found in [8]. The therapeutic pool walls are assumed well insulated. The other assumptions to be made are constant properties of water such as specific heat and mass density. Sliding Mode Control (SMC) is especially suited for use in problems such as the one at hand because of its insensitivity to certain kinds of disturbances [9-11]. The applications of SMC for thermal systems have been reported, as in [3, 12, 13].

This paper is organized as follows. Section II presents the mathematical model which contains the mathematical formula based on the thermodynamicals principle adn mass balance equation for therapeutic pool. Section III presents the design of the Sliding Mode Control. Section IV presents the result of simulation, and the last section presents the conclusions based on the purpose of the paper with future work suggestion.

\section{MATHEMATICAL MODEL}

In this section, two differential equations are used for describing the mathematical model of therapeutical pool that is shown in Fig. 1.

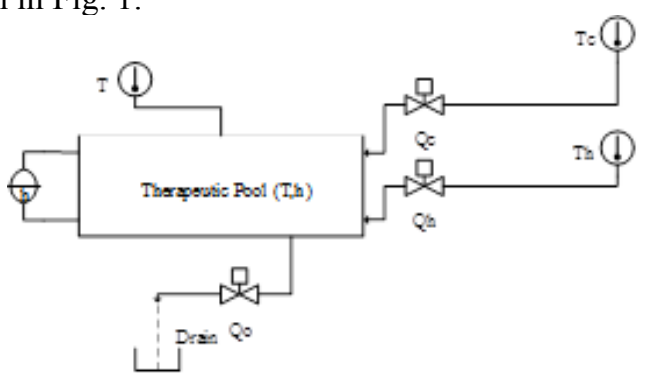

Fig. 1. Schematic diagram of therapeutic pool. 
The mathematical model of therapeutical pool is derived based on the thermodynamics principle and mass balance equation. The equations are written as follows:

$$
\begin{gathered}
\frac{d V}{d t}=Q_{h}+Q_{c}-Q_{0} \\
\frac{d E}{d t}=\rho c_{p} Q_{c} T_{c}+\rho c_{p} Q_{h} T_{h}-\rho c_{p} Q_{0} T-h A\left(T-T_{s}\right)
\end{gathered}
$$

Thus, we can derive equation (1) to get water level rate of change as follows:

$$
\frac{\mathrm{d}(\mathrm{AH})}{\mathrm{dt}}=Q_{\mathrm{h}}+Q_{\mathrm{c}}-Q_{\mathrm{o}}
$$

in which $\mathrm{A}$ is assumed to be constant, thus

$$
\begin{aligned}
& \mathrm{A} \frac{\mathrm{dH}}{\mathrm{dt}}=Q_{\mathrm{h}}+Q_{\mathrm{c}}-Q_{0} \quad \text { or } \\
& \frac{\mathrm{dH}}{\mathrm{dt}}=\frac{1}{\mathrm{~A}}\left(\mathrm{Q}_{\mathrm{h}}+\mathrm{Q}_{\mathrm{c}}-\mathrm{Q}_{0}\right)
\end{aligned}
$$

Equation (4) shows the relationship between level rate of change with inlet and outlet water flow. We can derive the temperature rate of change based on equation (2), by substituting $\mathrm{E}=\rho \mathrm{AH} c_{\mathrm{p}} \mathrm{T}$, and we obtain this equation as follows:

$$
\frac{d\left(\rho A H c_{p} T\right)}{d t}=\rho c_{p} Q_{c} T_{c}+\rho c_{p} Q_{h} T_{h}-\rho c_{p} Q_{0} T-h A\left(T-T_{s}\right)
$$

Furthermore, by assuming the water properties are constant, thus

$$
\frac{d(A H T)}{d t}=Q_{c} T_{c}+Q_{h} T_{h}-Q_{0} T-\frac{h A}{\rho c_{p}}\left(T-T_{s}\right)
$$

In equation (6), $\mathrm{T}$ and $\mathrm{h}$ are time-varying-variable, thus

$\mathrm{AT} \frac{\mathrm{d}(\mathrm{H})}{\mathrm{dt}}+\mathrm{AH} \frac{\mathrm{d}(\mathrm{T})}{\mathrm{dt}}=\mathrm{Q}_{\mathrm{c}} \mathrm{T}_{\mathrm{c}}+\mathrm{Q}_{\mathrm{h}} \mathrm{T}_{\mathrm{h}}-\mathrm{Q}_{0} \mathrm{~T}-\frac{\mathrm{hA}}{\rho \mathrm{c}_{\mathrm{p}}}\left(\mathrm{T}-\mathrm{T}_{\mathrm{s}}\right)$

Substitute equation (4) into equation (7), we get

$$
\begin{aligned}
& A H \frac{d(T)}{d t}=Q_{c}\left(T_{c}-T\right)+Q_{h}\left(T_{h}-T\right)-\frac{h A}{\rho c_{p}}\left(T-T_{s}\right) \\
& \frac{d T}{d t}=\frac{1}{A H}\left[Q_{c}\left(T_{c}-T\right)+Q_{h}\left(T_{h}-T\right)-\frac{h A}{\rho c_{p}}\left(T-T_{s}\right)\right]
\end{aligned}
$$

Equation (8) shows the relationship between temperature rate of change with the energy carried with the inlet water. In order to get the convective heat transfer coefficient, we assume the heat transfer over flat plate, written as in the following equations [8].

$$
\begin{gathered}
h=\frac{k}{A / P} N_{\mathrm{u}} \\
\frac{\mathrm{dT}}{\mathrm{dt}}=\frac{1}{\mathrm{AH}}\left[\mathrm{Q}_{\mathrm{c}}\left(\mathrm{T}_{\mathrm{c}}-\mathrm{T}\right)+\mathrm{Q}_{\mathrm{h}}\left(\mathrm{T}_{\mathrm{h}}-\mathrm{T}\right)-\frac{\mathrm{hA}}{\rho \mathrm{c}_{\mathrm{p}}}\left(\mathrm{T}-\mathrm{T}_{\mathrm{s}}\right)\right]
\end{gathered}
$$

$$
R a_{L}=\frac{g \beta\left(T-T_{\infty}\right)(A / P)^{3}}{v^{2}} P_{r}
$$

The therapeutic pool parameters value to be used in this simulation are shown in Table 1.

Table 1. Therapeutic pool parameters and value.

\begin{tabular}{|c|c|}
\hline Parameter & Value \\
\hline Hot water temperature & $\mathrm{T}_{\mathrm{h}}=70^{\circ} \mathrm{C}$ \\
\hline Cold water temperature & $\mathrm{T}_{\mathrm{c}}=27^{\circ} \mathrm{C}$ \\
\hline Environment temperature & $\mathrm{T}_{\infty}=31^{\circ} \mathrm{C}$ \\
\hline Cold water flow rate & $\mathrm{Q}_{\mathrm{c}}=0.0008 \mathrm{~m}^{3} / \mathrm{s}$ \\
\hline Hot water flow rate & $\mathrm{Q}_{\mathrm{h}}=0.0008 \mathrm{~m}^{3} / \mathrm{s}$ \\
\hline Drainage flow rate & $\mathrm{Q}_{\mathrm{o}}=0.0008 \mathrm{~m}^{3} / \mathrm{s}$ \\
\hline Bottom area & $\mathrm{A}=3 \mathrm{~m} 2$ \\
\hline Pool perimeter & $\mathrm{P}=8 \mathrm{~m}$ \\
\hline Air thermal conductivity & $\mathrm{k}, \mathrm{W} / \mathrm{m}^{0} \mathrm{C}$ \\
\hline Nusselt number & $\mathrm{Nu}$ \\
\hline Rayleigh number & $\mathrm{Ra} \mathrm{L}$ \\
\hline Prandtl number & $\mathrm{P}_{\mathrm{r}}$ \\
\hline Gravitational acc. & $\mathrm{g}=9.81 \mathrm{~m} / \mathrm{s}^{2}$ \\
\hline Volumetric expansion coeff & $\beta=1 /{ }^{\circ} \mathrm{C}$ \\
\hline Kinematic viscosity & $\mathrm{v}, \mathrm{m}^{2} / \mathrm{s}$ \\
\hline Pool Temperature & $\mathrm{T},{ }^{\circ} \mathrm{C}$ \\
\hline Pool Height & $\mathrm{H}, \mathrm{m}$ \\
\hline
\end{tabular}

\section{DESIGN OF SLIDING MODE CONTROL}

The aim of SMC design is to eliminate the error and its derivative. In this system, error is defined by the difference between actual mixed water temperature and desired temperature which can be represented mathematically as follows:

$$
e(t)=T_{D}(t)-T(t)
$$

where $T_{D}(t)$ is the desired temperature and $T(t)$ is actual mixed water temperature in the therapeutic pool. The expression of $n^{\text {th }}$ order sliding function can be written as follows [14]:

$$
s(t)=\left(\frac{d}{d t}+\lambda\right)^{n-1} e
$$

Thus the expression of $2^{\text {nd }}$ order form of equation (13) is as follows:

$$
S=\dot{\theta}+\lambda_{e}
$$

where $\lambda>0$ is the slope of the sliding surface. The SMC discontinuous control law is given by following equation:

$$
U_{D}=K \operatorname{sgn}(S)
$$


where $\mathrm{K}$ is manual tuning constant and has responsibility in reaching mode. The main disadvantage of SMC is chattering phenomenon. Chattering is high-frequency oscillation occurs around the equilibrium point. Chattering problem can be solved if $U_{D}$ is designed as follow [15].

$$
U_{D}=K \frac{s}{|s|+\delta}
$$

where $\delta$ is chattering suppression factor and will be adjusted manually to eliminate chattering. The system modeled with $1^{\text {st }}$ order differential equation, thus we need $S=0$ condition to design $\mathrm{U}_{\mathrm{C}}$. SMC continuous control law can be written as follows.

$$
U_{c}=\frac{A H}{F_{h}\left(T_{h}-T\right)}\left(\frac{h}{H \rho c_{p}}\left(T-T_{s s}\right)-\frac{F_{c}}{A H}\left(T_{c}-T\right)-\lambda\left(T-T_{D}\right)\right)
$$

After we get the SMC continuous and discontinuous control law, we can proceed to make the complete SMC law which is written as follows:

$U_{(t)}=\frac{A H}{F_{h}\left(T_{h}-T\right)}\left(\frac{h}{H \rho c_{p}}\left(T-T_{s o}\right)-\frac{F_{c}}{A H}\left(T_{c}-T\right)-\lambda\left(T-T_{D}\right)\right)+K \frac{s}{|s|+\delta}$

Furthermore, the closed loop schematic diagram of therapeutic pool plant controlled by SMC is shown in Fig. 2.

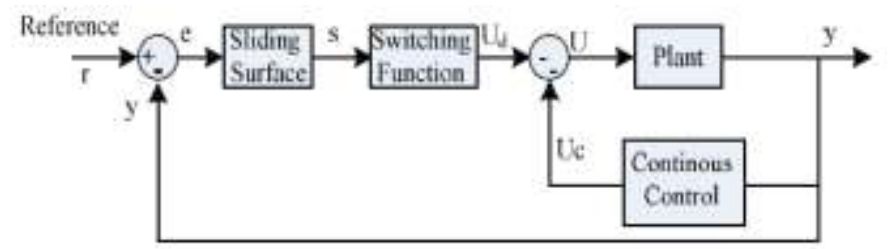

Fig. 2. Closed loop schematic diagram of SMC [16].

\section{SimUlation RESUlTS}

The simulated therapeutic pool plant is a non-linear singleinput single-output (SISO) system. The inputs are both cold and hot water temperature and volumetric flow rate. The controlled input is the hot valve and the controlled variable is the mixed water temperature in therapeutic pool. System response with SMC controller is shown in Fig. 3.

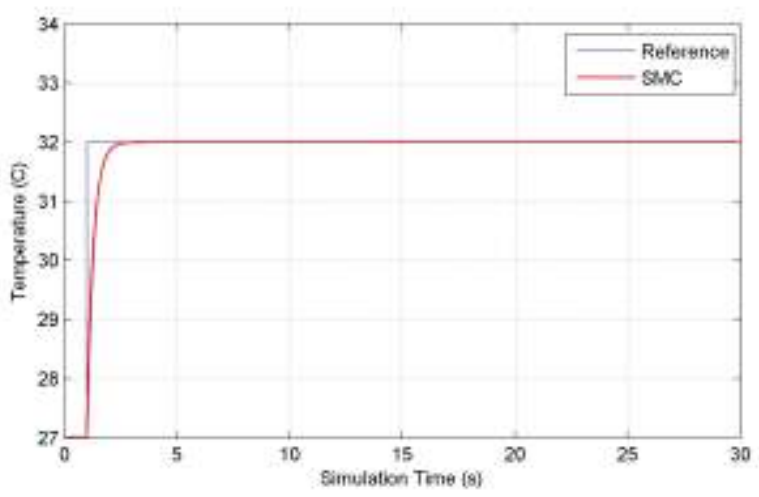

Fig. 3. System response with SMC controller.

System response with PID controller is shown in Fig. 4.

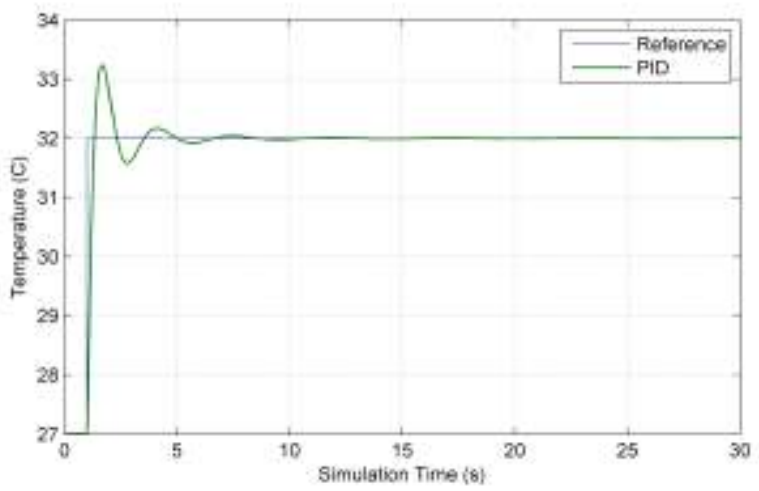

Fig. 4. System response with PID controller.

System response with PID neural network model controller is shown in Fig. 5.

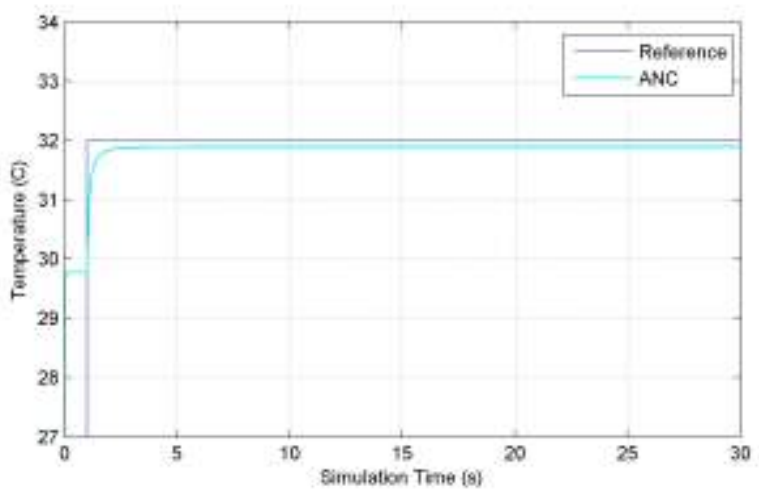

Fig. 5. System response with ANC.

The comparison of system response with various control methods is shown in Fig. 6. 


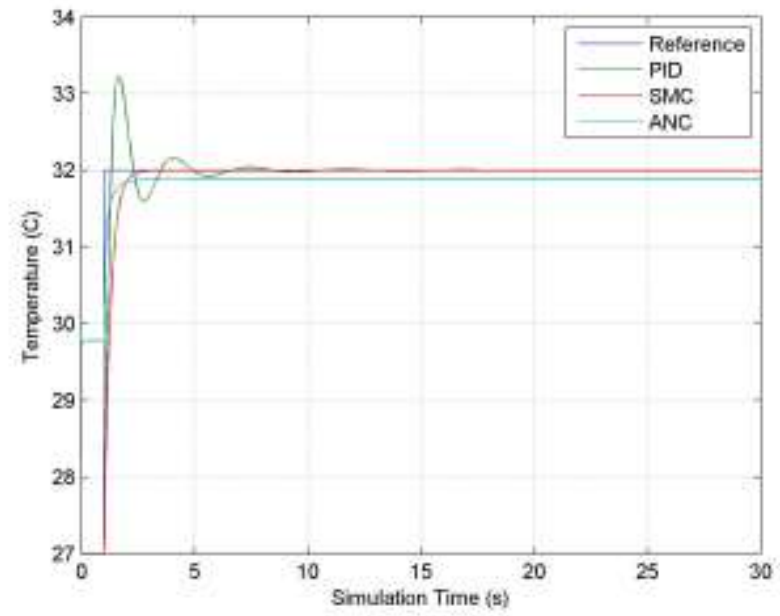

Fig. 6. Comparison of system responses.

Time response parameters of the three control methods without disturbance are shown in Table 2.

Table 2. Time response parameter without disturbance.

\begin{tabular}{cccc}
\hline Parameters & PID & ANC & SMC \\
\hline Rise time (s) & 0.237 & 1.243 & 1.270 \\
Settling time (s) & 4.514 & NaN & 1.987 \\
Overshoot (\%) & 3.827 & 0 & 0 \\
SSE (\%) & 0.006 & 0.322 & 0 \\
\hline
\end{tabular}

Introduce time-varying cold and hot water temperature to the system as shown in Fig. 7 and Fig. 8, respectively.

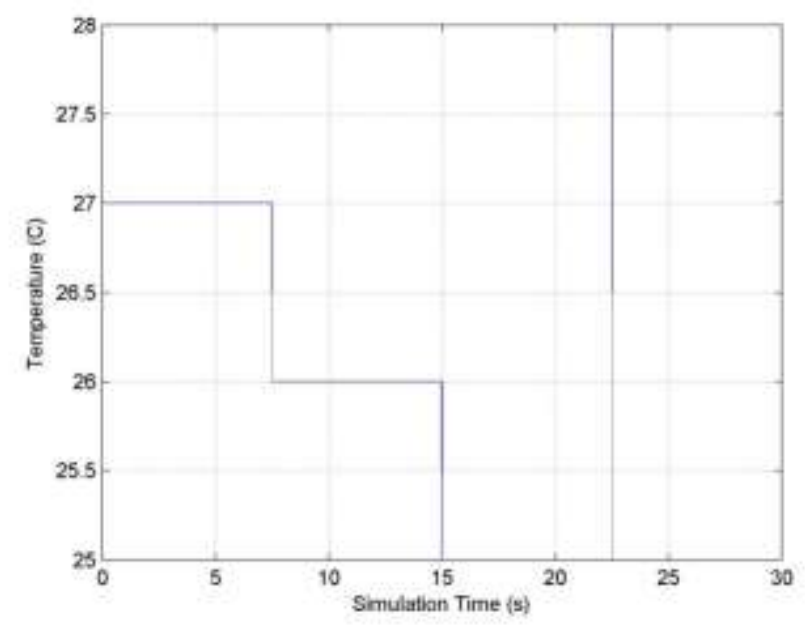

Fig. 7. Cold temperature as disturbance.

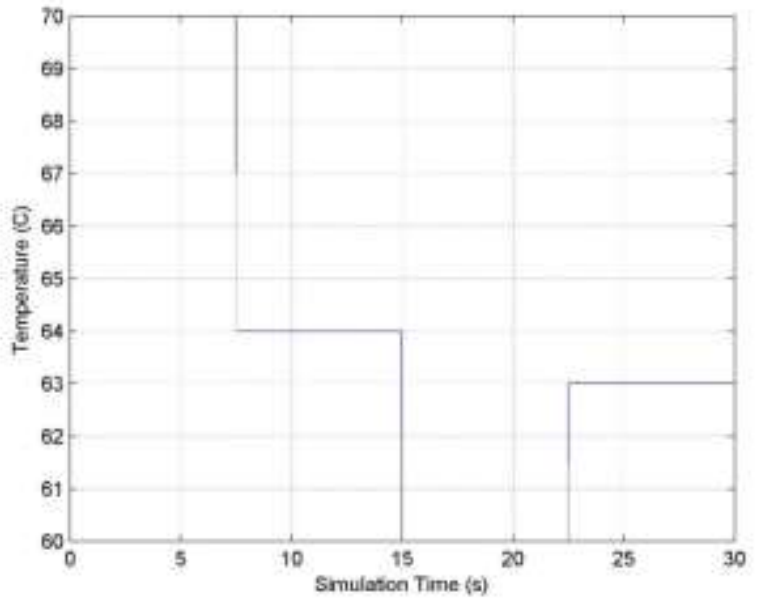

Fig. 8. Hot temperature as disturbance.

The comparison of the system responses with cold and hot inlet water temperature variation as disturbances is shown in Fig. 9. Time response parameters with disturbance are shown in Table 3.

Table 3. Time response parameter without disturbance.

\begin{tabular}{cccc}
\hline Parameters & PID & ANC & SMC \\
\hline Rise time (s) & 1.299 & 1.094 & 1.272 \\
Settling time (s) & 29.651 & NaN & 1.988 \\
Overshoot (\%) & 2.322 & 3.971 & 0 \\
SSE (\%) & 0.139 & 0.177 & 0 \\
\hline
\end{tabular}

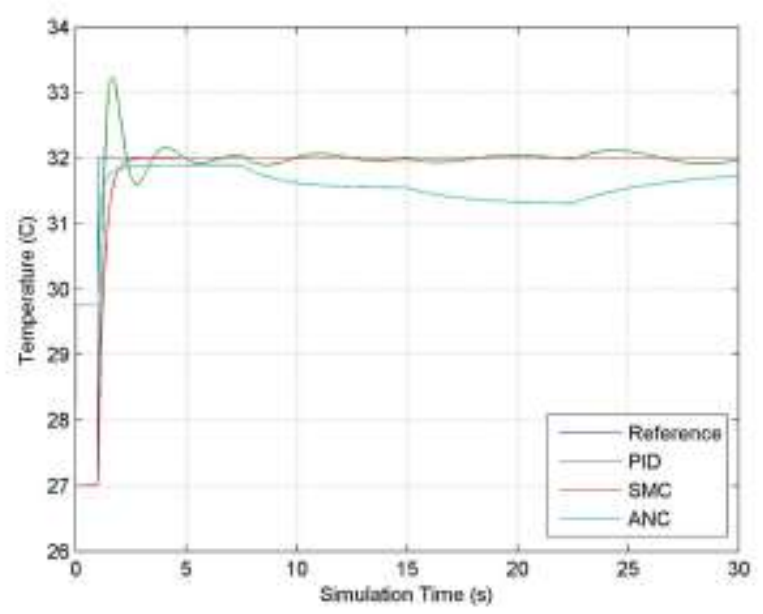

Fig. 9. Comparison of system response with disturbance.

\section{CONCLUSION}

Based on simulation results showed that SMC control method has better performance than the conventional PID and neural network controller. The SMC is able to reject the varying disturbance due to cold and hot water temperature variation. For future work, it will be valuable to implement the SMC controller into hardware. 


\section{ACKNOWLEDGEMENTS}

We would like to thank the Ministry of Research, Technology and Higher Education of the Republic of Indonesia. This work was financially supported by Development in Science and Technology for Research Grand No. : 022/SP2H/LT/DRPM/II/2016 from Directorate General of Higher Education, the Ministry of Research, Technology and Higher Education of the Republic of Indonesia, Indonesia.

\section{REFERENCES}

[1] J.C. Montagna, B.C., Santos, C.R. Battistuzzo, A.P. Lourero, "Effect of Aquatic Physiotherapy on the Improvement of Balance and Corporal Symmetry in Stroke Survivors, Vol. 7 (4), pp. 1182-1187, 2014.

[2] P. Kusumaastuti, "Hidroterapi, Pulihkan Otot dan Sendi yang Kaku," Accessed on Friday, April $10^{\text {th }} 2016,<$ www.gayahidupsehat.com>.

[3] H. Richter, F. Figueroa, "Sliding Mode Control of a Thermal Mixing Process," Nasa's Technology, Research, and Science.

[4] H. Richter, "Robust Nonlinear Control of a Thermal Mixing Process", The 2004 IEEE International Conference on Control Applications, 2004.

[5] B.B. Musmade, R.K., Munje, B.M., Patre, Design of Sliding Controller to Chemical Processes for Improved Performance", International Journal of Control and Automation, Vol. 4, No. 1, pp. 15-31, 2011.

[6] Munadi, T. Naniwa, "Experimental Verification of Adaptive Dominant Type Hybrid Adaptive and Learning Controller for Trajectory Tracking of Robot Manipulators", Journal of Robotics and Mechatronics, vol. 25 (4), pp. 737-747, May 2013.

[7] Munadi, M. A. Akbar, "Simulation of Fuzzy Logic Control for DC Servo Motor using Arduino Based on MATLAB/Simulink", Intelligent Autonomous Agents, Networks and Systems (INAGENTSYS), 2014 IEEE International Conference, pp. 42-46, August 2014.

[8] Y.A. Cengel, "Heat Transfer: A Practical Approach", $2^{\text {nd }}$ ed, p. 463-469, 2015.

[9] U. Itkis, “Control Systems of Variable Structure,” John Wiley, 1977.

[10] V. Utkin, "Variable Structure Systems with Sliding Modes," IEEE Transcription on Automatic Control, Vol. 22 (2), pp. 212-222, 1977.

[11] V.I. Utkin, "Sliding Modes in Control Optimization," Springer-Verlag, 1992.

[12] T. Xiao, H.X. Li, "Sliding Mode Control Design for a Rapid Thermal Processing System," Chemical Engineering Science, Elsevier, Vol. 143, pp. 76-85, 2016.

[13] C.T. Chen, "A Sliding Mode Control Strategy for Temperature Trajectory Tracking in Batch Processes," 8th IFAC Symposium on Advanced Control of Chemical Processes, pp. 644-649, July, 2012.

[14] Slotine, Jean-Jacques E. and Li, Weiping, Applied Nonlinear Control, Prentice Hall, 1991.

[15] T. Toms, Hepsiba D., "Comparison of PID Controller with a Sliding Mode Controller for a Coupled Tank System," International Journal of Engineering Research \& Technology, Vol. 3, No. 2, 2014.

[16] H. Abbas, S. Asghar, S. Qamar, "Sliding Mode Control for CoupledTank Liquid Level Control System," International Conference on Frontiers of Information Technology, 2012. 